\title{
Acute chagas outbreaks: molecular and biological features of Trypanosoma cruzi isolates, and clinical aspects of acute cases in Santander, Colombia
}

\author{
Martha Lucía Díaz', Sandra Leal², Julio César Mantilla ${ }^{1}$, Alfredo Molina-Berríos ${ }^{4,5}$, Rodrigo López-Muñoz,
} Aldo Solari ${ }^{3}$, Patricia Escobar ${ }^{2}$ and Clara Isabel González Rugeles ${ }^{1,7^{*}}$

\begin{abstract}
Background: Outbreaks of acute Chagas disease associated with oral transmission are easily detected nowadays with trained health personnel in areas of low endemicity, or in which the vector transmission has been interrupted. Given the biological and genetic diversity of Trypanosoma cruzi, the high morbidity, mortality, and the observed therapeutic failure, new characteristics of these outbreaks need to be addressed at different levels, both in Trypanosoma cruzi as in patient response. The aim of this work was to evaluate the patient's features involved in six outbreaks of acute Chagas disease which occurred in Santander, Colombia, and the characteristics of Trypanosoma cruzi clones isolated from these patients, to establish the potential relationship between the etiologic agent features with host behavior.

Methods: The clinical, pathological and epidemiological aspects of outbreaks were analyzed. In addition, Trypanosoma cruzi clones were biologically characterized both in vitro and in vivo, and the susceptibility to the classical trypanocidal drugs nifurtimox and benznidazole was evaluated. Trypanosoma cruzi clones were genotyped by means of mini-exon intergenic spacer and cytochrome b genes sequencing.

Results: All clones were DTU I, and based on the mini-exon intergenic spacer, belong to two genotypes: G2 related with sub-urban, and G11 with rural outbreaks. Girón outbreak clones with higher susceptibility to drugs presented G2 genotype and $C / T$ transition in $C y t b$. The outbreaks affected mainly young population ( \pm 25.9 years), and the mortality rate was $10 \%$. The cardiac tissue showed intense inflammatory infiltrate, myocardial necrosis and abundant amastigote nests. However, although the gastrointestinal tissue was congestive, no inflammation or parasites were observed.

Conclusions: Although all clones belong to DTU I, two intra-DTU genotypes were found with the sequencing of the mini-exon intergenic spacer, however there is no strict correlation between genetic groups, the cycles of the parasite or the clinical forms of the disease. Trypanosoma cruzi clones from Girón with higher sensitivity to nifurtimox presented a particular G2 genotype and $C / T$ transition in Cyt $b$. When the diagnosis was early, the patients responded well to antichagasic treatment, which highlights the importance of diagnosis and treatment early to prevent fatal outcomes associated with these acute episodes.
\end{abstract}

Keywords: Trypanosoma cruzi, Acute Chagas disease, Outbreaks, Nifurtimox, Benznidazole, DTU I, Colombia

\footnotetext{
* Correspondence: cig@uis.edu.co

${ }^{1}$ Grupo de Inmunología y Epidemiología Molecular (GIEM), Facultad de

Salud, Universidad Industrial de Santander, Bucaramanga, Colombia

${ }^{7}$ Escuela de Microbiología, Facultad de Salud, Carrera 32 \#29-31, Oficina 419,

Universidad Industrial de Santander, Bucaramanga, Colombia

Full list of author information is available at the end of the article
} 


\section{Background}

Chagas disease (CD) caused by Trypanosoma cruzi affects about 8 million people in Latin America [1]. In Colombia, it is estimated that 1.3 million people are infected, and 3.6 million are at risk [2]. The department of Santander has a seroprevalence rate close to $40 \%$ in most endemic areas [2]. CD has two clinical phases: acute phase is usually asymptomatic, and chronic phase in which about 10-30 \% of infected patients develop symptoms [3], and $70 \%$ could remain asymptomatic, (indeterminate form) [3]. Chronic Chagasic cardiomyopathy (CCC) is the most common and severe manifestation, and occurs after $10-20$ years following the infection. The digestive forms of $\mathrm{CD}$ occur almost exclusively in Argentina, Brazil, Chile and Bolivia, although they have also been reported in Mexico, and Colombia [3-5].

Differences in biological characteristics among T. cruzi isolates have been demostrated $[6,7]$, and the correlation between genotypic and phenotypic aspects of parasite behaviour was confirmed by Revollo et al. [8] Some of these biological features of the T. cruzi genotypes are relevant, since they might be associated with pathogenesis or drug susceptibility [9]. In this regard, efforts to analyze the relevance of these differences in pathogenesis of $\mathrm{CD}$ are necessary. T. cruzi has a high degree of genetic variability, and is classified in six phylogenetic groups (discrete typing units, DTUs), categorized from TcI to TcVI [10]. In Colombia, most isolates obtained from diverse sources have been classified as TcI, but in the Santander Department, TcII have also been found in chronic cases of CD [11-15]. A new subdivision within TcI parasites has been reported using nuclear and mitochondrial molecular markers as miniexon and cytochrome $b$ gene sequencing, respectively [16-18]. Some of these TcI variants seem to be associated with humans and peridomestic and sylvatic transmission cycles [18]. However, recent reviews identified that although there are genetic and geographical structures, these are not strictly associated with cycle and host origins [19].

No vaccines are available so far, and there are only two registered drugs, the nitrofuran derivative, nifurtimox (Lampit, Bayer) and 2-nitroimidazole benznidazole (Radanil, Roche), being especially effective in newborns, and in the acute phase [1]. However, these drugs have severe limitations of long protocols of treatment and potential harmful side-effects. Also, T. cruzi strains with natural resistance have been reported [20], and these drugs have limited efficacy, depending on the phase of infection, the patient's age, and the involved endemic area. [21, 22] This last point could be related to differences in drug susceptibility among $T$. cruzi genetic variants $[1,20]$.

In addition to chronic $\mathrm{CD}$, acute cases of $\mathrm{CD}$ have been reported early in French Guiana and Brazil since 1941 [23]. Currently, close to $78 \%$ of the acute outbreaks are related with oral transmission through contaminated food $[23,24]$. Most of them are reported in the Amazonian region and Southern Brazil, Venezuela, and French Guiana [24-30]. Although, in most of the acute cases TcI parasites were found; TcII, TcIII, TcIV and TcV have also been documented [31-34]. In Colombia, the first acute CD report was in the Norte de Santander Department, in 1992 [35]. Subsequently, in the period 2002-2005, other cases were reported from several geographic regions of Colombia, including Santander Department [36]. In 2006, nine new acute CD cases were reported [37]. Between 2008 and 2009 outbreaks of probable oral transmission were reported in Santander [33, 38]. The purpose of this study was to evaluate the clinical and pathological features of patients involved in six outbreaks from Santander, between 2008 to 2010, and the biological and genetic characteristics of $T$. cruzi clones isolated from twelve of these patients. We report that all clones were DTU I, with intra-DTU genotypes G2 and G11. These genotypes had differential distribution in urban and rural areas, and the G2 genotype was more susceptible to drugs analysed.

\section{Methods}

\section{Ethics, consent and permissions}

Patients were included in the study after written informed consent, according to the declaration of Helsinki. For children enrolled in the study, written informed consent was given by parents. The study was approved by the Ethical Committee of the Universidad Industrial de Santander (approval number 012/2009). Patients diagnosed with CD were treated according to the guidelines of the Colombian Health Ministry.

All animal handling protocols were performed according to the "Guide for the Care and Use of Laboratory Animals", from the National Institute of Health, USA (National Research Council (US) Committee for the Update of the Guide for the Care and Use of Laboratory Animals. Guide for the care and use of laboratory animals (8th edition), and approved by the Institutional Ethical Committee at the Faculty of Medicine, University of Chile (Protocol CBA\# 0448 FMUCH).

\section{Study areas}

Six outbreaks of acute CD were reported in five localities of the Santander Department. Santander is one of the 32 departments of Colombia located in the northeastern part of the country. The area is $30,537 \mathrm{~km}^{2}$ with a population of 2'086.649 inhabitants, 87 municipalities and Bucaramanga as its capital. Santander Department is considered the third most endemic department for CD in Colombia [39]. According to the Santander Health authorities, six municipalities are considered highly endemic, some of which had improvement of rural housing and vector control program 
[40]. Municipalities where outbreaks occurred are considered of low endemicity (incidence rates below 3 000 cases per 100000 inhabitants), except Lebrija and San Vicente de Chucurí with an incidence rate of 12 to 24000 cases per 100000 inhabitants, and where there are no reports of domiciliated vectors. The first outbreak occurred in December 2008 in the town of Lebrija, in 2009 there were two outbreaks, one in a peri-urban area of the Bucaramanga city (Barrio Bucaramanga), and another in Piedecuesta. In 2010 three outbreaks occurred, one in the town of San Vicente de Chucurí, another in the town of Girón, and the third in a peri-urban area of Bucaramanga city (Barrio Morrorico) (Fig. 1).

\section{Parasites}

Twelve T. cruzi isolates from 30 patients of six outbreaks of acute CD (2008 to 2010) in Santander Department from Colombia were used in this study (Table 1). In addition, the $338 \mathrm{clBb}(\mathrm{TcI})$ and Sylvio X10 (TcI) were used as a chronic isolate and reference strain, respectively (non-outbreak strains). The parasites were isolated by hemocultures as previously described [41]. The isolates were cloned using an isolation method of single colonies on solid medium [42], resulting in 5-10 clones per isolate, for each isolate one clone was selected. The selected clones from the different outbreaks were maintained in
LIT medium and subsequently submitted to the different analysis. The parasites codes, date and place of collection, and gender and age of the patients are showed in Table 1.

\section{Genotyping of $T$. cruzi isolates}

Seven independent genetic markers were used to genotype the T. cruzi clones. Mini-exon intergenic spacer (SL-IR), 24Sa rRNA D7 domain and 18S rRNA, were amplified as previously described [43, 44]. The mitochondrial gene Cytochrome Oxidase subunit II (COII) was characterized by nested PCR followed by Alu I restriction endonuclease. The RFLP analysis was done in $6.0 \%$ polyacrylamide gel and revealed by silver staining [45], and the Cytochrome b $(C y t b)$ gen was amplified as previously described [46]. Additionally, HSP60 and GPI genes were analysed [47]. DNA from T. cruzi strains, representing major genetic groups TcI and TcII were used as controls for all PCR assays. In addition, to determine the degree of genetic similarity of the parasites with the sequences already reported in GenBank, mini-exon PCR products were sequenced from T. cruzi clones in the ABI 3730xl DNA analyzer (Applied Biosystems, Foster City, CA, USA). Purification and direct sequencing of DNA amplicons of Cytb gene were performed by MACROGEN (Seoul, South Korea).

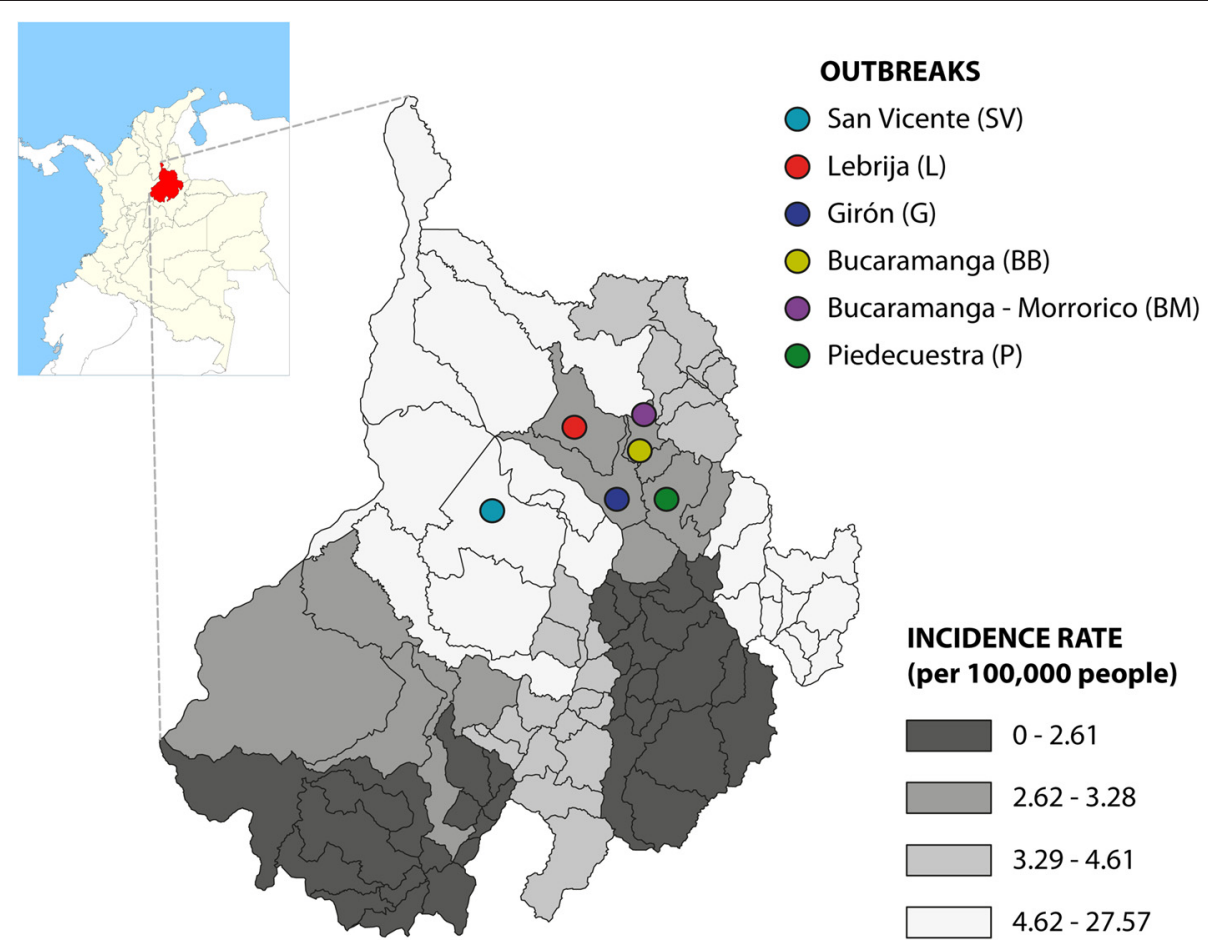

Fig. 1 Geographical distribution and location of the municipalities in Santander, Colombia where acute Chagas outbreaks occurred. Gray-scaled map shows the Santander department. The Chagas Disease incidence in each municipality is indicated with one of the four gray scales indicated in the picture. The geographical distribution of the outbreaks described in this article is specified with the colored circles 
Table 1 Trypanosoma cruzi isolates from acute Chagas disease in Santander, Colombia

\begin{tabular}{|c|c|c|c|c|}
\hline ID isolate & Outbreak & Year & Gender & Age (years) \\
\hline 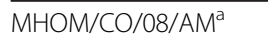 & Lebrija (L) & 2008 & $M$ & 23 \\
\hline $\mathrm{MHOM} / \mathrm{CO} / 08 / \mathrm{JCR}^{\mathrm{a}}$ & Lebrija(L) & 2008 & M & 21 \\
\hline $\mathrm{MHOM} / \mathrm{CO} / 08 / \mathrm{EH}$ & Lebrija (L) & 2008 & M & 22 \\
\hline $\mathrm{MHOM} / \mathrm{CO} / 09 / \mathrm{JCHV}^{\mathrm{a}}$ & Barrio Bucaramanga (BB) & 2009 & $\mathrm{~F}$ & 3 \\
\hline MHOM/CO/09/PEGAL & Piedecuesta (P) & 2009 & M & 6 \\
\hline MHOM/CO/10/SMAY & San Vicente (SV) & 2010 & $\mathrm{~F}$ & 24 \\
\hline MHOM/CO/10/GUICA & San Vicente (SV) & 2010 & $\mathrm{~F}$ & 53 \\
\hline MHOM/CO/10/SATHE & Girón (G) & 2010 & $\mathrm{~F}$ & 8 \\
\hline MHOM/CO/10/DATHE & Girón (G) & 2010 & $\mathrm{~F}$ & 3 \\
\hline $\mathrm{MHOM} / \mathrm{CO} / 10 / \mathrm{OSGO}$ & Girón (G) & 2010 & M & 19 \\
\hline MHOM/CO/10/JLM & Girón (G) & 2010 & M & 19 \\
\hline MHOM/CO/10/HEMA & Morrorico Bucaramanga (MB) & 2010 & M & 43 \\
\hline
\end{tabular}

${ }^{\mathrm{a} F a t a l}$ cases

\section{Editing and alignment}

SL-IR sequences and $C y t b$ genes were edited using BioEdit software v.7.0.9 [48], and aligned with ClustalW algorithm [49]. For SL-IR the sequence was resolved for 192 positions taking into account the microsatellite region at the beginning of the sequences and with the putative motif (GT)n (ATGT)n (AT)n (GT)n and the end with GCGTGT [19], and for $C y t b$ the sequence was resolved for 516 bp. Reference genotypes were obtained from the GenBank database: AM259467 and AM259479.1. The sequences were analysed with the entire microsatellite region and without this motif as was described [19].

\section{Biological features of $T$. cruzi clones in vitro Differentiation of T. cruzi epimastigotes}

T. cruzi epimastigotes $\left(1 \times 10^{6}\right.$ parasites $\left./ \mathrm{mL}\right)$ were cultured in Grace's Insect Media (Sigma, St. Louis, USA) with $10 \%$ hiFCS at $28{ }^{\circ} \mathrm{C}$. Both, numbers of epimastigotes and culture medium-derived trypomastigote $(\mathrm{cmDT})$ were counted under a microscope using a hemocytometer chamber after $2,5,7,10,12,14,17,19$, and 21 days. Epimastigotes with flagellum and which were mobile were counted. Determination of day of maximum $\mathrm{cmDT}$, and the $\%$ of $\mathrm{cmDT}$ $(E+T)$ were calculated at each point of time.

\section{Release-kinetic of mammalian cells derived trypomastigotes (cellDT)}

Vero cells in RPMI 1640 (Gibco, Grand Island, USA) culture medium supplemented with $10 \%$ hiFCS were allowed to attach to 24-well plates. After $24 \mathrm{~h}$, a final number of $1 \times 10^{5}$ adherent cells $/ \mathrm{mL}$ were infected with $5 \times 10^{5} \mathrm{cmDT} / \mathrm{mL}$ at $37^{\circ} \mathrm{C}, 5 \% \mathrm{CO}_{2}$ for $24 \mathrm{~h}$. Free parasites were removed by washing twice with culture medium. After $24 \mathrm{~h}$, released and mobile cellDT were counted microscopically every day for 15 days using eosin yellow.

\section{Infectivity to cultured mammalian cells}

Vero cells (ATCC: CCL-81), cultured in RPMI medium (10\% hiFCS at $37^{\circ} \mathrm{C}, 5 \% \mathrm{CO}_{2}$ and $95 \%$ humidity), were plated on glass coverslips in 24-well plates and infected with cellDT at a 10:1 parasite-to-cell ratio for $24 \mathrm{~h}$. Noninternalized parasites were removed by washing with culture medium. Infected cultures were incubated for 24, 48 and $72 \mathrm{~h}$. The cells were fixed with $70 \%$ methanol and stained with Giemsa and the percentage of infected cells and the numbers of amastigotes per cell were calculated $[25,26]$.

\section{Drug susceptibility test}

For amastigote drug susceptibility test, Vero cells were infected with cellDT as described above. Infected cells were treated with benznidazole or nifurtimox ranging from 0.3 to $300 \mu \mathrm{M}$ for $120 \mathrm{~h}$. The treatment schedule included a second dose after $72 \mathrm{~h}$. Control untreated cells were maintained with culture medium without drug. After $120 \mathrm{~h}$, the cultures were fixed and stained with Giemsa. The percentage of infected cells was evaluated by counting 300 Vero cells per coverslip for each condition by light microscopy. Drug activity was determined by the percentage of infected cells in treated and untreated cultures. The percent of infected cells before the start of the drug treatment was determined in all strains.

\section{In vivo behavior of $T$. cruzi clones \\ Mice infection}

BALB/c mice $(n=6)$ of $20-25$ g were inoculated orally with $10^{6} \mathrm{cmDT}$ of each $T$. cruzi clones studied from the mortal acute cases (JCR, and JChV), and control clones for comparative purposes $338 \mathrm{clBb}$ and Sylvio X10). Parasitemia was registered to assure infection after the $4^{\text {th }}$ day of inoculation. End point for cardiac studies was established at the $25^{\text {th }}$ day post infection. 


\section{Heart extraction and histopathological studies from infected mice}

Surviving mice were euthanized at day 25 p.i. and their hearts were extracted. Hearts were longitudinally sectioned to further analysis by histopathology.

\section{qPCR of heart tissue from infected mice}

Heart samples extracted from euthanized animals were homogenized, and the total genomic DNA was isolated using a Wizard ${ }^{\oplus}$ Genomic DNA Purification Kit (Promega, Madison, USA) following the manufacturer's instructions. A Real Time PCR TaqMan assay was used to quantify parasite DNA with method previously described [50]. The data are expressed as the ratio of $T$. cruzi DNA to murine DNA.

\section{Statistical analysis}

The in vitro growth kinetics, metacyclogenesis, cell infectivity, and drug activities experiments were performed in triplicate, with at least two independent experiments. For all experiments, analysis of variance with Bonferroni post-test and $T$ test were made, with a confidence level of $95 \%$, using the Graphpad Prism software version 5.0. Values of $p<0.05$ were considered significant. The drug activities of benznidazole and nifurtimox were expressed as the drug concentration able to decrease in a $50 \%$ $\left(\mathrm{IC}_{50}\right)$ the number of infected cells. The $\mathrm{IC}_{50}$ values were determined by four-parameter dose response curve fitting, using the Xlfit4TM program (ID Business Solution, Guildford, UK).

\section{Results}

\section{Epidemiological, clinical and pathological findings}

The highest percentage of cases came from the town of Lebrija (33.3 \%), 23.3 \% from Bucaramanga, $16.6 \%$ from Piedecuesta and Girón and 10 \% from San Vicente de Chucurí. Three outbreaks were from rural areas and three were peri-urban areas. One important epidemiological feature in five of the outbreaks was the presence of marsupial and insects in the peridomiciliary and absence of domiciliated triatomines.

The average age of the patients was 25.9 years and 54\% were male and $46 \%$ were female. The most common symptoms were fever and malaise (100\%), abdominal pain $(83.3 \%)$ and tachycardia (75 \%). Heart failure was present in $66.6 \%$ and pericardial effusion in $41.6 \%$ of cases (Table 2). The mortality rate was $10 \%(3 / 30)$ and one patient required a heart transplant to save her.

\section{Lebrija outbreak}

This outbreak involved 10 individuals. The first patient diagnosed, three family members, two colleagues and four workers of the parents'farm. All patients shared food in this farm, four months before diagnosis. The
Table 2 Signs and symptoms of patients with acute Chagas disease from Santander, Colombia

\begin{tabular}{ll}
\hline Signs and symptoms & $\mathrm{N}(\%)$ \\
\hline Fever & $12(100)$ \\
Malaise & $12(100)$ \\
Abdominal pain & $10(83.3)$ \\
Tachycardia & $9(75)$ \\
Facial edema & $8(66.6)$ \\
Headache & $8(66.6)$ \\
Heart failure & $8(66.6)$ \\
Nausea & $7(58.3)$ \\
Breathing difficulty & $6(50)$ \\
Chest pain & $6(50)$ \\
Vomits & $5(41.6)$ \\
Legs edema & $5(41.6)$ \\
Pericardial effusion & $5(41.6)$ \\
Cough & $4(33.3)$ \\
\hline
\end{tabular}

diagnosis of acute $\mathrm{CD}$ was performed by autopsy of the first patient and the other patients were diagnosed by laboratory tests, (parasitological and/or serological tests). All patients were treated with nifurtimox, nevertheless, one of the co-workers of the first patient also died as a consequence of heart failure. The parent's house was built with wall of brick with a roof made of tile and cane, and the floor is made of cement. The kitchen zone was located in the back part of the house, it was observed that there were no access to animals and there were no windows. Three T. cruzi isolates were obtained from these patients.

In summary, in this outbreak two fatal cases occurred. The case 1 was diagnosed post-mortem, and whose findings were soft tissue edema, bilateral hydrothorax, ascites, pulmonary edema and cardiomegaly with dilatation of all cavities. Histological examination of the heart showed dense inflammatory infiltrate with diffuse involvement of the myocardium, abundant cysts occupying most of the myocardial fibers, T. cruzi amastigote occurrence, and extensive areas of myocardial necrosis (Fig. 2a, b). At the level of the esophagus and stomach congestion was observed marked with lymphocytic infiltrate in the absence of parasites.

The second case was a patient diagnosed by serological tests; this patient was treated with nifurtimox, with satisfactory evolution. A week following discharge from the hospital, the patient was readmitted with dyspnea, orthopnea, cough, hemoptysis but no fever or pain. Clinical evaluation revealed evident arrhythmic heart sounds, decreased breath sounds, and hepatomegaly. The electrocardiogram revealed atrial fibrillation with high ventricular response, and chest radiograph evidenced right pleural effusion. He 


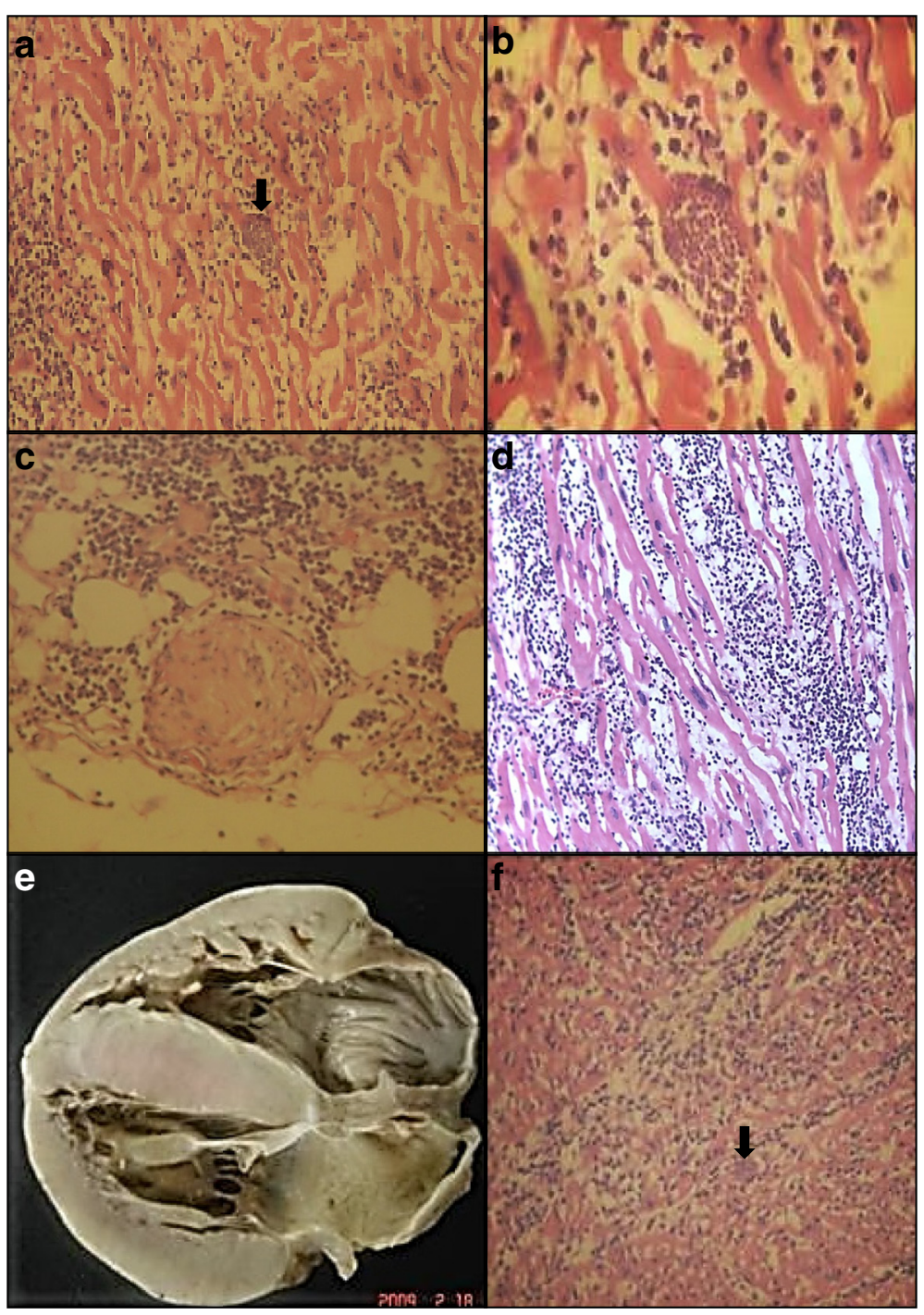

Fig. 2 Histopathology analysis of hearts from acute Chagas cases occurred in Santander, Colombia. Figures a, and $\mathbf{b}$. Heart sections of the patient 1 from Lebrija outbreak. c. Heart section of the patient 2 from Lebrija outbreak. d. Heart section of the patient from San Vicente outbreak. e. Overview of the heart of the patient from Bucaramanga (BB) outbreak. f. Heart section of the same patient showed in panel e. (Bucaramanga outbreak). Amastigote nests are indicated by black arrows

was moved to the intensive care unit with congestive heart failure diagnosis, and there, the patient had progressive deterioration of cardiocirculatory function and developed cardiogenic shock refractory to the administration of intravenous fluids and inotropic drugs, and he died. The autopsy showed predominantly mononuclear inflammatory infiltrate of lymphocytes in the epicardium and neural ganglia, extending diffusely throughout the myocardium. Numerous changes were also observed in the myocardial fibers with necrosis and scarce amastigote nests (Fig. 2c). Esophagus, small intestine and colon showed marked congestion without inflammatory disorder, or parasites.

\section{Bucaramanga outbreak}

The Bucaramanga outbreak occurred in a peri-urban area of Bucaramanga city in February 2009 and involved five cases of one family: a one year old girl who died, her mother, her sister, her aunt, and her uncle. The diagnosis of acute $C D$ was performed on autopsy of the index case and the other patients were diagnosed by laboratory tests, (parasitological and/or serological tests). The cases had symptoms about 15 days before the girl death. All patients were treated with nifurtimox. The house is located in an area surrounded by a wooded area with the presence of wild animals: rats, marsupials and monkeys. $63 \%$ of the neighbors recognized the insect vector, $23 \%$ 
reported having seen them in the house, in bedroom walls, ceilings and flying out of the house (17\%) [38]. One $T$. cruzi isolate was obtained. The girl was diagnosed by autopsy whose findings were: generalized edema, bilateral pleural effusions and pericardial ascites, cardiomegaly (Fig. 2e), linfoplasmohistiocitaria global severe myocarditis by $T$. cruzi and amastigote nests (Fig. 2f). Pulmonary edema, hepatosplenomegaly and generalized mesenteric lymphadenitis were also observed.

\section{Piedecuesta outbreak}

In April of 2009 in a rural area of the Piedecuesta locality occurred the third outbreak which involved five cases of one family: one boy of six years old, the mother, the grandmother, a sister and one uncle. The diagnosis was made by clinical symptoms and confirmed by parasitological (boy) and serological tests (family). The house is located in an area surrounded by a wooded area. The kitchen was located at the back of the house and was easily accessible from the outside. Near the house was a deposit which generated dirt and proliferation of insect vectors and different animals, however, at home and nearby no triatomines were found. All patients were treated with nifurtimox and they recovered. One T. cruzi isolate was obtained.

\section{San Vicente de chucurí outbreak}

In a rural area of the San Vicente de Chucurí locality in February 2010 occurred an outbreak involving three cases: one woman of twenty four years old whose diagnosis was made by parasitological test, and two other cases: the woman's mother and a colleague who were identified by serological test. The house was located in the vicinity of the town, built with walls, roofs and floors with solid materials and was surrounded by grasslands, palm trees and a wooded area where insect vectors and marsupials were found. The patients were treated with benznidazole. Two T. cruzi isolates were obtained.

The young woman had a positive hemoculture, and clinically presented chest pain, tachycardia, pericardial effusion, evolving to heart failure. Therefore, the patient was subjected to heart transplantation to save her. In the pathological analysis, the infected heart was normal size and shape, with $355 \mathrm{~g}$ of weight. It presented little lymphocytic infiltration in the epicardium and the myocardium presented severe necro-inflammatory lesions represented by a dense infiltrate of lymphocytes, plasma cells and histiocytes and multiple areas of necrosis with multiple nests occupying almost the entire cytoplasm of some myocardial fibers, in which punctate structures were found inside with diameter between 1-2 microns, which corresponded to T. cruzi amastigotes. The coronary arteries had normal characteristics and no plaques were identified (Fig. 2d).

\section{Girón outbreak}

In May of 2010 in a peri-urban area of the Girón locality there was an outbreak involving five cases in one family: one man of 19 years old who had symptoms 15 days after the diagnosis was made by parasitological and serological test. The other cases were: two sisters, a young man, and a mother. All patients shared a meal and all were treated with benznidazole. The house was made of brick and cement floor, but near to the house were palm trees with the presence of triatomines. Four T. cruzi isolates were obtained.

\section{Morrorico outbreak (Bucaramanga)}

In the Morrorico district, a peri-urban area of Bucaramanga city (BM), in June of 2010 there was an outbreak with two cases: one man (index case) and his wife. The diagnosis of the index case was made by parasitological and serological test and the main symptoms were fever, headache, malaise, facial edema, tachycardia and heart failure. His wife had fever and malaise. The kitchen of the house was open to the yard that is very close to fruit trees and a wooded area. From the survey it was known that the patient hunted animals like armadillos and opossums for food. The patients were treated with benznidazole. One $T$. cruzi isolate was obtained.

\section{Genotyping of $T$. cruzi isolates}

Genetic characterization with seven different markers allowed us to identify that all the T. cruzi isolates of acute cases belong to DTU I (Additional file 1: Figure S1). Sequencing and alignments of SL-IR showed that T. cruzi clones were grouped into two distinct genotypes: G2 $(50 \%)$ with the putative motif in microsatellite $(\mathrm{GT})_{8}$, $(\mathrm{ATGT})_{2},(\mathrm{AT})_{1}$ and $(\mathrm{GT})_{0}{ }^{19}$ or Tc Ib previously described [17] for clones of Girón, Barrio Bucaramanga and Morrorico; and G11 (50 \%) with the putative motif in microsatellite $(\mathrm{GT})_{6},(\mathrm{ATGT})_{1},(\mathrm{AT})_{1}$ and $(\mathrm{GT})_{0}$ or Tc Id for clones from Lebrija, San Vicente, and Piedecuesta (Fig. 3a). The analysis of 192 nucleotides without microsatellite region showed 11 variable sites and 181 conserved sites. Although, the alignment of the sequences of $C y t b$ gene showed similarity of all clones with genotype $C$ previously described [51, 52], three clones of Girón, Barrio Bucaramanga, Piedecuesta and one of San Vicente exhibited a $\mathrm{C} / \mathrm{T}$ transition at position 237 (50 \%) unreported previously (Fig. 3b).

\section{Biological features of $T$. cruzi clones in vitro Differentiation of T. cruzi epimastigotes}

Kinetics of epimastigote growth between outbreak isolated parasites and non-outbreak (338clBb and Silvio X10) strains are showed in Fig. 4a, b and c. Sylvio X10 strain grows faster than the parasites isolated from Lebrija patients (EH, JCR, and AM, Fig. 4a) and also from Morrorico, 


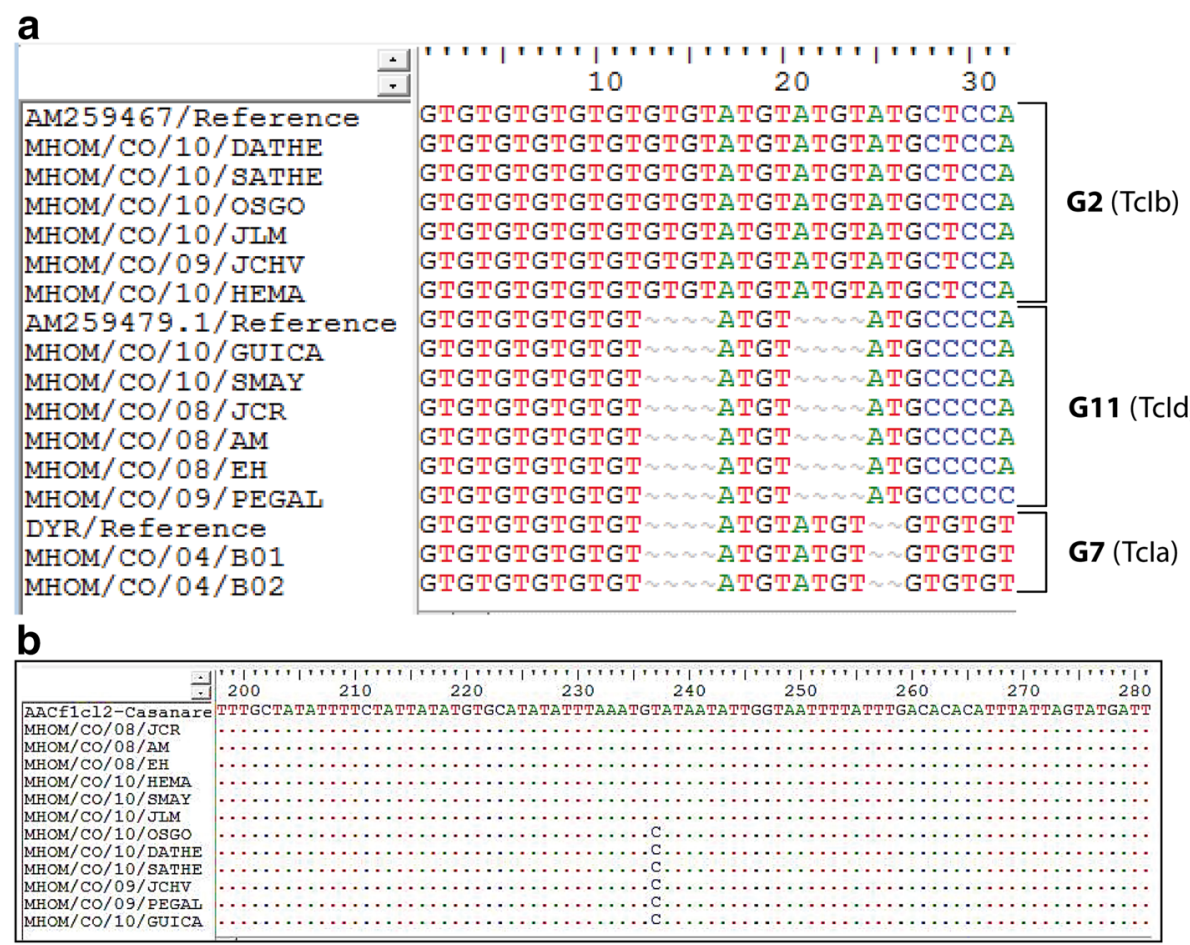

Fig. 3 Sequence alignment of the SL-IR microsatellite region, and Tcl sub-classification of T. cruzi clones obtained of patients with acute Chagas disease in Santander, Colombia. a. Alignment of the SL-IR microsatellite region and Tcl sub classification. T. cruziisolates and reference strains $\mathbf{b}$. Alignment of the Cyt $b$
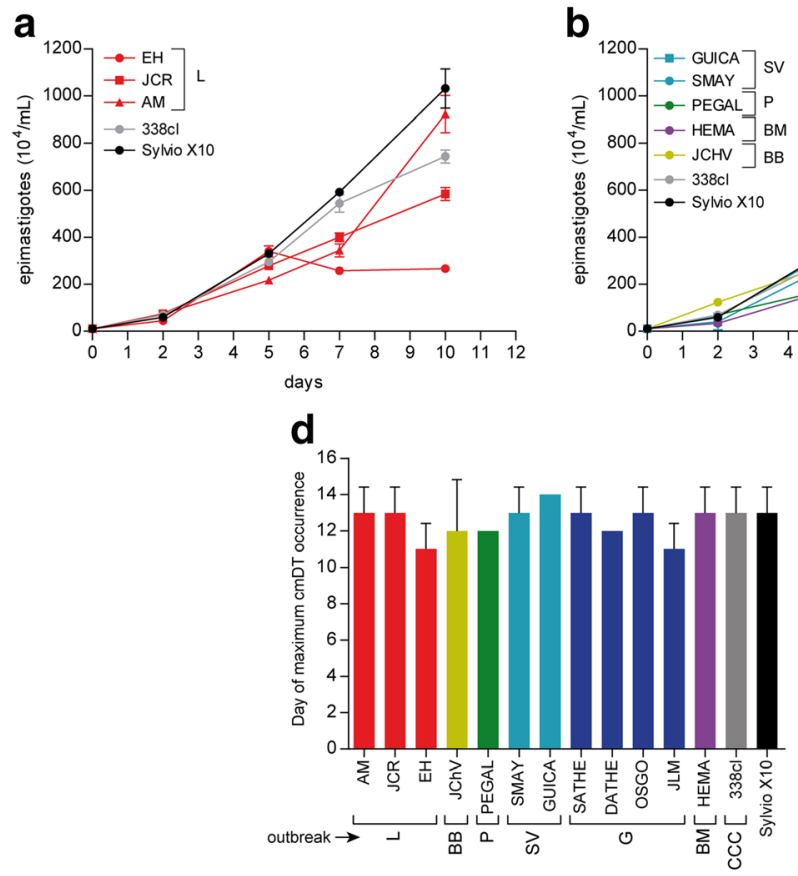
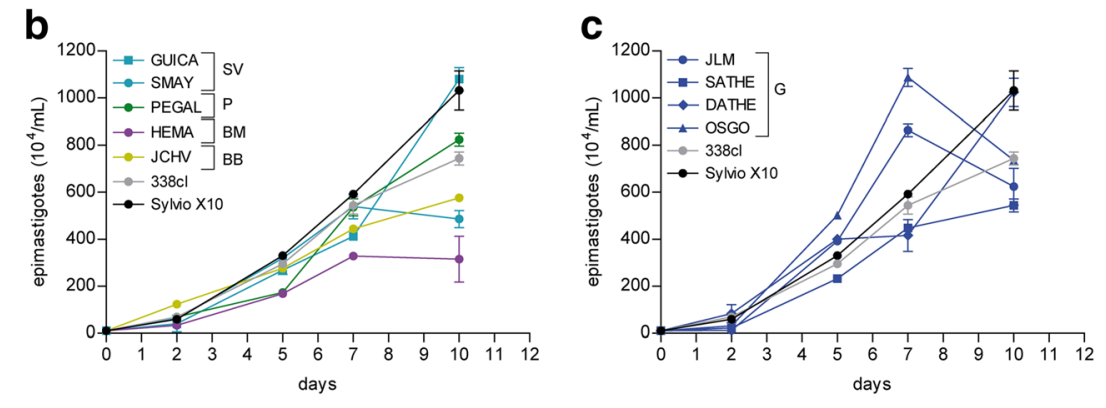

e

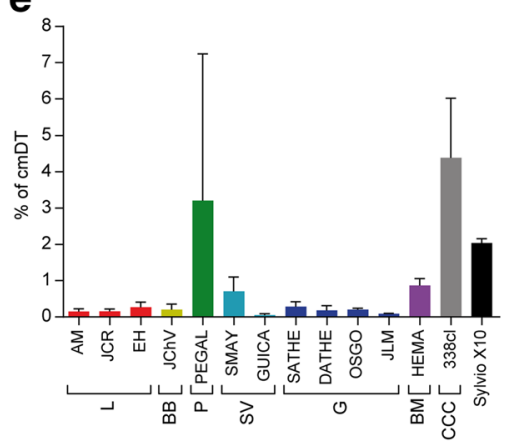

Fig. 4 Differentiation of T. cruzi epimastigotes. Epimastigotes were cultured in Grace's medium and the number of epimastigotes and culture medium-derived trypomastigote (cmDT) were evaluated. Figures $\mathbf{a}, \mathbf{b}$, and $\mathbf{c}$. Epimastigote numbers after 2, 5, 7, 10 and 12 days of assay. $\mathbf{d}$. Day of maximum numbers of $\mathrm{cmDT}$. e. Maximum percentage of $\mathrm{cmDT}$ in total parasites (epimastigotes plus $\mathrm{cmDT}$ ). Each experiment was evaluated in triplicate and repeated two times 
Barrio Bucaramanga and San Vicente patients (Fig. 4b). Parasites isolated from Girón patients (Fig. 4c), showed different patterns of growth: OSGO and JLM grow faster than the others showing the maximum parasite numbers at 7 days, SATHE is the slowest one, and DATHE showed similar pattern of growth than Sylvio X10. The nonoutbreak isolates used in this study showed a maximal number of epimastigotes $\left(74-103 \times 10^{6}\right.$ parasites $\left./ \mathrm{mL}\right)$ at 10 days (Fig. 4).

For metacyclogenesis in axenic cultures, $\mathrm{cmDT}$ reached a maximum between 10 and 15 days, without significant difference between all clones (Fig. 4d). The numbers of cmDT in acute clones compared with reference strains were different $(p<0.05)$. Transformation values below $1 \%$ on outbreak clones compared with 4.5 and $2 \%$ on $338 \mathrm{clBb}$ and Sylvio X-10 clones respectively were observed. The only exception among the acute clones was the Piedecuesta clone that reached a $3 \%$ of cmDT transformation (Fig. 4e).

\section{Parasites behavior in mammalian cell culture}

All T. cruzi clones were able to infect Vero cells and transform to amastigotes, showing an increased number of intracellular parasites up to $72 \mathrm{~h}$ (data not shown). A slight increase of the per cent of infected cells in all outbreak clones after infection was registered with values in the range of $30-48 \%$ at $24 \mathrm{~h}, 33-70 \%$ at $48 \mathrm{~h}$ and $43-$ $74 \%$ at $72 \mathrm{~h}$. A statistically significant $(p>0.05)$ higher degree of cell infectivity was observed in the reference Sylvio X10 strain with values of $92.3 \%$ at $24 \mathrm{~h}, 93.3 \%$ at $48 \mathrm{~h}$ and $96.6 \%$ at $72 \mathrm{~h}$. All the tested clones produced cellDT from Vero cells as is showed in Fig. 5a, b and c. JLM and SATHE (both Giron clones) and EH (Lebrija clone) reached the maximum number of cellDT earlier than Sylvio X10 clone and JCHV (Barrio Bucaramanga clone) produced a greater number of cellDT than Sylvio $\mathrm{X} 10$ clone.

\section{Drug susceptibility}

We also studied the susceptibility of each clone to nifurtimox and benznidazole. At $\mathrm{IC}_{50}$ level, the ranges of susceptibilities were from $2.15 \pm 0.17$ to $38.28 \pm 1.70 \mu \mathrm{M}$ to nifurtimox, and $5.30 \pm 0.46$ to $32.50 \pm 3.72 \mu \mathrm{M}$ to benznidazole. Most of the clones were more susceptible to nifurtimox than benznidazole, $p<0.05$ (Fig. $5 \mathrm{~d}$ and e). Overall, the most sensitive clones to nifurtimox were those belonging to the Girón outbreak: SATHE, DATHE, OSGO and JLM and Morrorico clone (HEMA), these clones showed

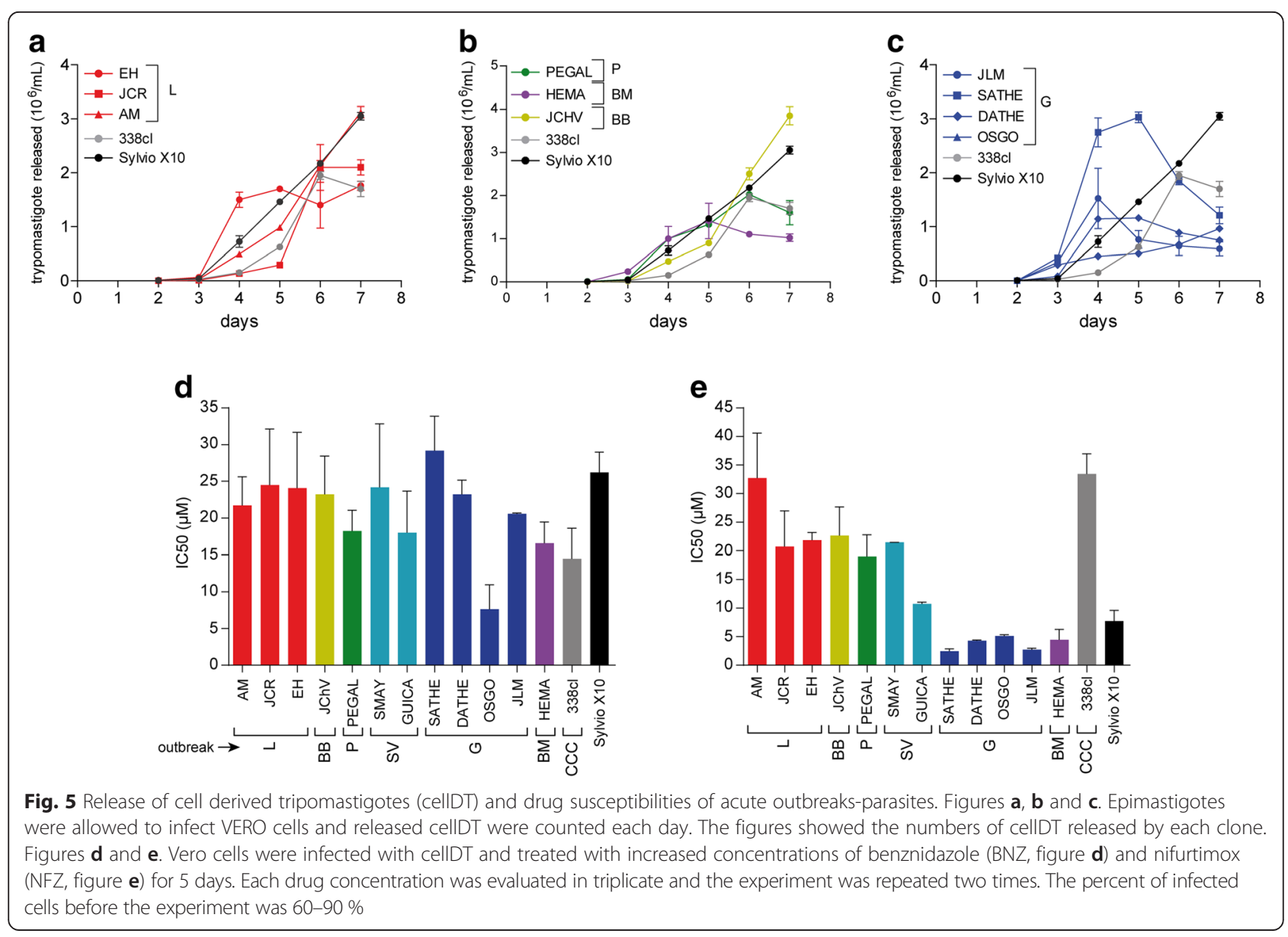


a similar susceptibility pattern as the Sylvio X10 reference clone (Fig. 5d).

\section{In vivo behavior of clones}

To explore the possibility of an oral infection in our previous cases, we studied the infectivity by oral route of two clones from lethal cases (JChV and JCR clones). Also, we used the $338 \mathrm{clBb}$ clone, obtained from a chronic case, as a control. $10^{6} \mathrm{cmDT}$ from the JChV, JCR and $338 \mathrm{clBb}$ clones were inoculated by oral route in $\mathrm{BALB} / \mathrm{c}$ mice and the outcome of the infection was compared with the Sylvio $\mathrm{X} 10$ clone, inoculated by the same route. All clones inoculated by the oral route successfully infected BALB/c mice, which was corroborated by parasitemia analysis (data not shown). Only the JChV clone showed mortality at day 25 post infection ( 1 of 4 mice). The cardiac outcome of the infection was studied by histology (Table 3) and parasite load in cardiac tissue by qPCR (Fig. 6). As Table 3 shows, JChV-infected mice presented more inflammatory infiltrate and amastigote nests. This correlates with the qPCR quantification, where mice infected with JChV clone had $10^{4}$ more parasites than mice infected with Sylvio X 10 clone, used as reference. In addition, $66 \%$ (2 of 3) mice infected with the JChV clone showed one or more amastigote nests in the histopathology. JCR and $338 \mathrm{clBb}$ clones induced low inflammation in cardiac tissue, similar to Sylvio X10 infection. JCR-infected mice did not show amastigote nests, whereas $50 \%$ (2 of 4 ) of mice infected with $338 \mathrm{clBb}$ clone did, but to a lesser extent than the JChV infection (Fig. 6).

Table 3 Histopathology of tissues from mice with acute Chagas disease infected orally with experimental and control clones

\begin{tabular}{|c|c|c|c|}
\hline ID isolate & $\begin{array}{l}\text { Numbering } \\
\text { of mice } \mathrm{e}^{\mathrm{a}}\end{array}$ & $\begin{array}{l}\text { Inflammatory } \\
\text { infiltrate }\end{array}$ & $\begin{array}{l}\text { Amastigote } \\
\text { nests }\end{array}$ \\
\hline \multirow[t]{3}{*}{$\overline{\mathrm{MHOM} / \mathrm{CO} / 09 / \mathrm{JCHV}}$} & 1 & Moderate & $(0-1 / c 40 X)$ \\
\hline & 2 & Moderate & $(2-3 / c 40 X)$ \\
\hline & 3 & Abundant & None \\
\hline \multirow[t]{4}{*}{$\mathrm{MHOM} / \mathrm{CO} / 08 / \mathrm{JCR}$} & 1 & Scarce & None \\
\hline & 2 & Scarce & None \\
\hline & 3 & None & None \\
\hline & 4 & Scarce & None \\
\hline \multirow[t]{4}{*}{$\mathrm{MHOM} / \mathrm{CO} / 01 / 338 \mathrm{clBb}$} & 1 & Scarce & None \\
\hline & 2 & Scarce & None \\
\hline & 3 & Scarce & $(0-1 / c 40 X)$ \\
\hline & 4 & Scarce & $(0-1 / c 40 X)$ \\
\hline \multirow[t]{4}{*}{ Sylvio X10 } & 1 & Scarce & None \\
\hline & 2 & None & None \\
\hline & 3 & Scarce & None \\
\hline & 4 & Scarce & None \\
\hline
\end{tabular}

${ }^{\mathrm{a}}$ Numbering mice correlate with those shown in Fig. 6 (qPCR)

${ }^{\mathrm{b}} \mathrm{No}$. of amastigote nests found on examination $40 \mathrm{X}$

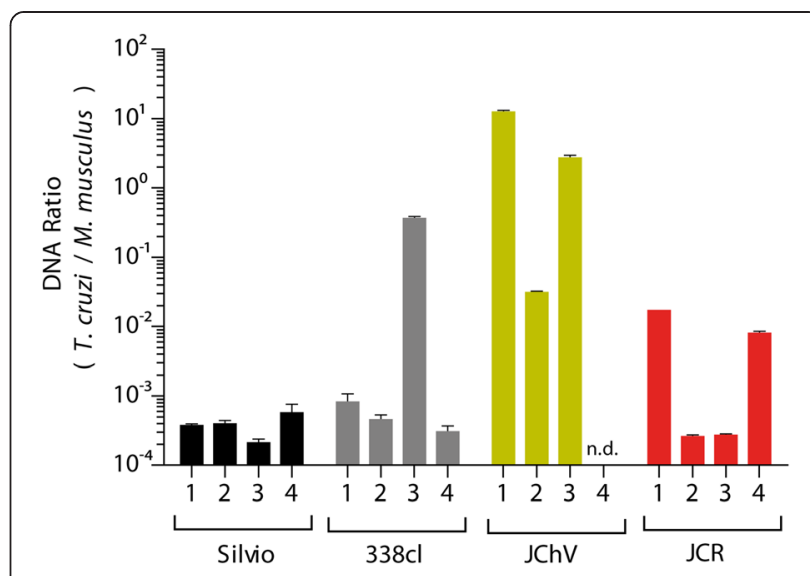

Fig. 6 Parasite load quantitation in heart from mice infected orally with T. cruzi clones. BALB/c mice were infected with four different clones and the parasite load was measured by qPCR at day 20 post-infection. Each bar represents one mouse measured by triplicate

\section{Discussion}

In Colombia, the departments with the highest infestation prevalence are located in the northeastern region [39], and since 1996 with the start of the vector control programs the number of domiciliated vectors decreased in highly endemic regions [53]. However, risk for human infection continue due to the natural infection rates in most sylvatic triatomine species that sporadically invade human dwellings, and the presence of houses close to palm trees occupied by triatomines and marsupials, both frequently infected $[54,55]$. The mammalian reservoirs infected as well as the massive displacement of human populations have increased the risk of transmission of $T$. cruzi even in areas of low endemicity. In Colombia, similar to what happened in northeast Brazil and Venezuela, these factors would be related to the increased outbreak reports of acute $\mathrm{CD}$ probably associated with oral transmission by food contamination [29, 32].

Santander has been the department with the highest number of outbreaks described (6/9). Although it is the third department of Colombia with triatomine house infestation [39], most of the outbreaks occurred in towns of low endemicity in which there are no reports of domiciliated triatomines. This finding and the fact that all cases occurred in rural or suburban areas with conditions favoring entry of sylvatic vectors or wild reservoirs to housing, support the hypothesis of oral transmission [29]. There is also the possibility of transmission by food contamination with urine or anal secretions of infected marsupials $[55,56]$. In five of the outbreaks of this study, the presence of marsupials in the peridomestic area was reported.

These outbreaks involved a small number of infected individuals, primarily associated with family outbreaks or individuals who attended and fed in the same house. The mortality was high especially during the first outbreak, 
probably due to late diagnosis by nonspecific clinical symptoms and because these cases were unusual in the region. The clinical suspicion is directed to other endemic diseases particularly dengue with similar early clinical symptoms. The frequency and the symptoms observed were similar to those in the majority of acute CD outbreaks reported [25, 27, 29, 32, 57, 58]. The histopathological findings of four hearts from patients, showed an intense inflammatory infiltrate in the interstitium, and the presence of amastigote nests in myocardial fibers. However, this inflammatory injury not only compromised the myocardial fibers but also damaged the ganglion cells and nerve fibers of the heart. These results contrast with chronic forms in which there is prevalence of fibrosis represented by fibroblasts and fibrocytes accompanied by matrix collagen deposit which replaced the myocardial fibers [15]. In digestive tract tissue of three autopsies performed, we observed marked congestion without tissue damage or the presence of parasites. The difference observed between the two patients of the Lebrija outbreak could be related to the fact that case 1 was not treated, and this correlates with the presence of an intense inflammatory infiltrate and numerous amastigote nests. Conversely, the second case that received treatment, also showed abundant inflammatory infiltrate, however, they presented nerve fiber damage and fewer groups of amastigotes. Damage to the nerve fiber generated conduction disturbances, which finally led to heart failure.

The isolates obtained in the six outbreaks belong to TcI that is the DTU most abundant and widely distributed in America, both in the domestic and sylvatic environments. In Colombia this DTU is dominant and it is associated with CCC [11, 12, 14]. Based on intergenic sequences of the mini-exon gene the clones were grouped into the G2 and G11 genotypes, which are also the most common in Colombia associated, not only with humans but also with vectors and reservoirs $[18,19]$. All clones in each outbreak were genetically identical; however, it is important to clarify that we only analysed one clone of each isolate; therefore we could not confirm the presence of multiclonal infections as has been described in Colombia and Venezuela $[33,59]$. Herrera et al, reanalysing the variability of the miniexon microsatellite region of molecular clones from 11 Latin American countries concluded, that although this region showed one interesting TcI variability that allowed some genetic and geographic structure; this structure was not associated with cycle and host origins [19], as previously proposed [14, 17]. However it is noteworthy that in our study the clones grouped as G2 (TcIb) occurred in suburbs of the city surrounded by forested areas with the presence of vectors, and reservoirs of marsupials or other rodents around houses, and the clones identified as G11 (TcId) occurred in rural dwellings suggesting both a sylvatic transmission. These results and recent reports from
Venezuela [59], and Colombia [33] of the presence of G2, G7 and G11 genotypes and multiclonal infections in acute CD patients support the notion that even though there is a grouping of genotypes, there is not strict correlation between genetic groups, and the cycles of the parasite or the clinical forms of the disease.

Although the majority of clones had similar biological features related with growth, metacyclogenesis and infectivity of mammalian cells, some differences were observed in Girón outbreak clones which reached maximum growth peaks and numbers of cellDT earlier than reference clone. These clones presented a particular G2 genotype and C/T transition in Cyt $b$. In the in vivo model of experimental infection, we show that oral inoculated T. cruzi were able to infect, and further reach the heart, inducing different clinical cardiac outcomes, similar to intraperitoneal infection (data not shown). JChV was the most infective clone; indeed, was the only lethal clone in Balb/c mice (one of four infected mice). This clone produced a greater number of cellDT than reference clone (Sylvio X10). This finding might be related to the fact that this isolate came from a fatal case.

T. cruzi clones obtained from all outbreaks were susceptible to both nitroheretocyclic drug in vitro, but nifurtimox was more active and showed more heterogeneity in the response than benznidazole. All clones from Girón outbreak, HEMA (Morrorico) and GUICA (San Vicente) showed increased susceptibility to nifurtimox compared with clones of other outbreaks. On the other hand, OSGO (Girón) also was the most susceptible to benznidazole. In a previous study with isolates from humans and vectors of Santander, similar results were obtained related to increased susceptibility to nifurtimox compared with benznidazole [22]. A study analysing acute outbreaks in Venezuela also showed that they were more susceptible to nifurtimox [60]. However, some studies of clinical follow-up of response to treatment with benznidazole of patients with acute $C D$ of outbreaks from Venezuela and Brazil reported the presence of parasites on blood cultures post-therapy indicating treatment failure [34, 61]. In contrast, in our work, the drug susceptibility in vitro was correlated with the response to treatment with benznidazole or nifurtimox and subsequent recovery in all patients that received chemotherapy.

The existence of differences in susceptibility to these compounds of a large number of T. cruzi isolates from different host, and geographic areas have been reported $[8,20]$, suggesting that TcI epimastigotes are more resistant to antichagasic drugs than other DTUs [8, 62]; however other surveys did not find differences in drug susceptibility in human chronic cases infected with TcI $[21,22]$. Although in our study all clones belong to TcI, we found that Girón clones that displayed higher sensitivity to nifurtimox presented a particular G2 genotype and $\mathrm{C} / \mathrm{T}$ transition in $C y t b$. Studies with human isolates 
obtained in acute phase of $C D$ in Brazilian Amazonia did not find differences in susceptibility to the drug between different DTUs [63]. However, they found statistically significant differences between $\mathrm{TcI}$ isolates from different regions of the Amazonia, similar results to those observed by us with the Girón outbreak clones. Similarly, in Venezuela outbreaks of oral acute CD, the major failure of the treatment was observed in patients infected with TcId (G11) showing greater susceptibility of the genotypes TcIb (G2) [34]. Alike, in Mexican isolates from acute and chronic cases found differences in susceptibility between different genotypes of TcI [64]. Further studies with these isolates could elucidate whether there are genotypic differences responsible for these resistance phenotypes, and thus achieve greater understanding of drug resistance mechanisms. In this study, when the diagnosis was appropriate and early, all treated cases responded well to antichagasic treatment, which highlights the importance of diagnosis and treatment early to prevent fatal outcomes associated with these acute episodes.

\section{Conclusions}

To summarize, all T. cruzi clones belong to DTU I and two intra-DTU genotypes were found with the sequencing of the mini-exon intergenic spacer, however there is no strict correlation between genetic groups, and the cycles of the parasite or the clinical forms of the disease. The cardiac tissue showed intense inflammatory infiltrate, myocardial necrosis and abundant amastigote nests. However, although the gastrointestinal tissue was congestive, no inflammation or parasites were observed. These findings represent a major contribution to studies aiming to associate the etiologic agent features with host behavior, and highlight the complexity of identifying characteristics of the parasite that could be involved in the pathogenesis of the acute Chagas disease.

\section{Additional file}

Additional file 1: Figure S1. Genotyping of T. cruzi isolates. Mini-exon intergenic spacer, 24Sa rRNA, 185 rRNA, glucose-6 phosphate isomerase (GPI), heat shock protein 60 (HSP60), and mitochondrial gene Cytochrome Oxidase subunit II (COII) genes were characterized. (TIF 386 kb)

\section{Competing interests}

None of the authors have any competing interests in the manuscript.

\section{Authors' contributions}

MLD was responsible for data collection, carried out the isolation, culturing, cloning and the molecular characterization of T.cruzi. SL and PE carried out the generation of resistant clones and the biological experiments in vitro; PE helped to draft the manuscript. RML and AMB were responsible for animal handling and carried out the biological experiments in vivo; RLM helped to draft the manuscript. JCM carried out the pathological studies. AS participated in the design of the study and helped to draft the manuscript. CIG conceived of the study, and participated in its design and coordination and drafted the manuscript. All authors reviewed and approved the final manuscript.

\section{Acknowledgements}

We thank all the participants in this study for their essential collaboration. This study was funded by Contract 734-2009, grant 110249326204 from the "Departamento Administrativo de Ciencia, Tecnología e Innovación, COLCIENCIAS", and "Universidad Industrial de Santander, Bucaramanga, Colombia". The funders had no role in study design, data collection and analysis, decision to publish, or preparation of the manuscript.

\section{Author details}

${ }^{1}$ Grupo de Inmunología y Epidemiología Molecular (GIEM), Facultad de Salud, Universidad Industrial de Santander, Bucaramanga, Colombia. ${ }^{2}$ Grupo de Investigación en Enfermedades Tropicales (CINTROP), Departamento de Ciencias Básicas, Escuela de Medicina, Universidad Industrial de Santander, Bucaramanga, Colombia. ${ }^{3}$ Programa de Biología Celular y Molecular, Instituto de Ciencias Biomédicas, Facultad de Medicina, Universidad de Chile, Santiago, Chile. ${ }^{4}$ Programa de Farmacología Molecular y Clínica, Instituto de Ciencias Biomédicas, Facultad de Medicina, Universidad de Chile, Santiago, Chile. ${ }^{5}$ Present address: Laboratorio de Farmacología y Farmacogenética, Instituto de Investigación en Ciencias Odontológicas (ICOD), Facultad de Odontología, Universidad de Chile, Santiago, Chile. ${ }^{6}$ Present address: Instituto de Farmacología y Morfofisiología, Facultad de Ciencias Veterinarias, Universidad Austral de Chile, Valdivia, Chile. 'Escuela de Microbiología, Facultad de Salud, Carrera 32 \#29-31, Oficina 419, Universidad Industrial de Santander, Bucaramanga, Colombia.

Received: 2 June 2015 Accepted: 19 November 2015

Published online: 26 November 2015

\section{References}

1. World Health Organization. Research priorities for Chagas disease, human African trypanosomiasis and leishmaniasis. World Health Organ Tech Rep Ser. 2012;xii:1-100.

2. Gutierrez R, Angulo VM, Tarazona Z, Britto C, Fernandes O. Comparison of four serological tests for the diagnosis of Chagas disease in a Colombian endemic area. Parasitology. 2004;129:439-44.

3. Rassi Jr A, Rassi A, Marin-Neto JA. Chagas disease. Lancet. 2010;375:1388-402.

4. Sanchez-Guillen M del C, Lopez-Colombo A, Ordoñez-Toquero G, GomezAlbino I, Ramos-Jimenez J, Torres-Rasgado E, et al. Clinical forms of Trypanosoma cruzi infected individuals in the chronic phase of Chagas disease in Puebla, Mexico. Mem Inst Oswaldo Cruz. 2006;101:733-40.

5. Florez O, Esper J, Higuera S, Barraza MF, Cabrera HB, Mantilla JC, et al. Chagasic megacolon associated with Trypanosoma cruzi I in a Colombian patient. Parasitol Res. 2010;107:439-42.

6. Sanchez G, Wallace A, Olivares M, Diaz N, Aguilera X, Apt W, et al. Biological characterization of Trypanosoma cruzi zymodemes: in vitro differentiation of epimastigotes and infectivity of culture metacyclic trypomastigotes to mice. Exp Parasitol. 1990;71:125-33.

7. Tibayrenc M. Genetic subdivisions within Trypanosoma cruzi (Discrete Typing Units) and their relevance for molecular epidemiology and experimental evolution. Kinetoplastid Biol Dis. 2003;2:12.

8. Revollo S, Oury B, Laurent JP, Barnabe C, Quesney V, Carrière V, et al. Trypanosoma cruzi: impact of clonal evolution of the parasite on its biological and medical properties. Exp Parasitol. 1998;89:30-9.

9. Macedo AM, Pena SD. Genetic Variability of Trypanosoma cruzi: Implications for the pathogenesis of Chagas disease. Parasitol Today. 1998;14:119-24.

10. Zingales B, Andrade SG, Briones MR, Campbell DA, Chiari E, Fernandes O, et al. A new consensus for Trypanosoma cruzi intraspecific nomenclature: second revision meeting recommends Tcl to TcVI. Mem Inst Oswaldo Cruz. 2009;104:1051-4.

11. Zafra G, Mantilla JC, Valadares HM, Macedo AM, Gonzalez Cl. Evidence of Trypanosoma cruzi II infection in Colombian chagasic patients. Parasitol Res. 2008;103:731-4.

12. Gonzalez Cl, Ortiz S, Solari A. Colombian Trypanosoma cruzi major genotypes circulating in patients: minicircle homologies by crosshybridization analysis. Int J Parasitol. 2010;40:1685-92.

13. Mantilla JC, Zafra GA, Macedo AM, Gonzalez Cl. Mixed infection of Trypanosomacruzi I and II in a Colombian cardiomyopathic patient. Hum Pathol. 2010;41:610-3. 
14. Ramirez JD, Guhl F, Rendon LM, Rosas F, Marin-Neto JA, Morillo CA. Chagas cardiomyopathy manifestations and Trypanosoma cruzi genotypes circulating in chronic Chagasic patients. PLoS Negl Trop Dis. 2010;4, e899.

15. Zafra G, Mantilla JC, Jacome J, Macedo AM, Gonzalez Cl. Direct analysis of genetic variability in Trypanosoma cruzi populations from tissues of Colombian chagasic patients. Hum Pathol. 2011;42:1159-68.

16. Herrera C, Bargues MD, Fajardo A, Montilla M, Triana O, et al. Identifying four Trypanosoma cruzi I isolate haplotypes from different geographic regions in Colombia. Infect Genet Evol. 2007;7:535-9.

17. Falla A, Herrera C, Fajardo A, Montilla M, Triana O, Vallejo GA, et al. Haplotype identification within Trypanosoma cruzi I in Colombian isolates from several reservoirs, vectors and humans. Acta Trop. 2009;110:15-21.

18. Ramirez JD, Duque MC, Guhl F. Phylogenetic reconstruction based on Cytochrome b (Cytb) gene sequences reveals distinct genotypes within Colombian Trypanosoma cruzi I populations. Acta Trop. 2011;119:61-5.

19. Herrera CP, Barnabe C, Breniere SF. Complex evolutionary pathways of the intergenic region of the mini-exon gene in Trypanosoma cruzi Tcl: a possible ancient origin in the Gran Chaco and lack of strict genetic structuration. Infect Genet Evol. 2013;16:27-37.

20. Filardi LS, Brener Z. Susceptibility and natural resistance of Trypanosoma cruzi strains to drugs used clinically in Chagas disease. Trans R Soc Trop Med Hyg. 1987;81:755-9.

21. Villarreal D, Barnabe C, Sereno D, Tibayrenc M. Lack of correlation between in vitro susceptibility to Benznidazole and phylogenetic diversity of Trypanosoma cruzi, the agent of Chagas disease. Exp Parasitol. 2004;108:24-31.

22. Luna KP, Hernandez IP, Rueda CM, Zorro MM, Croft SL, Escobar P. In vitro susceptibility of Trypanosoma cruzi strains from Santander, Colombia, to hexadecylphosphocholine (miltefosine), nifurtimox and benznidazole. Biomedica. 2009;29:448-55.

23. Raccurt CP. Trypanosoma cruzi in French Guinea: review of accumulated data since 1940. Med Trop (Mars). 1996;56:79-87.

24. Shaw J, Lainson R, Fraiha H. Epidemiology of the first autochthonous cases of Chagas' disease recorded in Belem, Para, Brazil. Rev Saude Publica. 1969;3:153-7.

25. Pinto AY, Valente SA, Valente VC. Emerging acute Chagas disease in Amazonian Brazil: case reports with serious cardiac involvement. Braz J Infect Dis. 2004:8:454-60.

26. Perez-Gutierrez E, Agrelo RS, Figueroa R. Technical recommendation on Chagas' disease epidemiology and prevention, focussing its transmission as a disease transmitted by food. Rev Soc Bras Med Trop. 2006;39:512-4.

27. Valente SA, da Costa Valente V, das Neves Pinto AY, de Jesus Barbosa Cesar M, dos Santos MP, Miranda CO, et al. Analysis of an acute Chagas disease outbreak in the Brazilian Amazon: human cases, triatomines, reservoir mammals and parasites. Trans R Soc Trop Med Hyg. 2009;103:291-7.

28. Pinto AY, Valente SA, Valente Vda C, Ferreira Junior AG, Coura JR. Acute phase of Chagas disease in the Brazilian Amazon region: study of 233 cases from Para, Amapa and Maranhao observed between 1988 and 2005. Rev Soc Bras Med Trop. 2008;41:602-14.

29. Alarcon De Noya B, Diaz-Bello Z, Colmenares C, Ruiz-Guevara R, Mauriello $L$, Zavala-Jaspe $R$, et al. Large urban outbreak of orally acquired acute Chagas disease at a school in Caracas, Venezuela. J Infect Dis. 2010;201:1308-15.

30. Carme B, Aune I, Nguyen G, Aznar C, Beaudet B. Four cases of acute chagasic myocarditis in French Guiana. Am J Trop Med Hyg. 2001;64:162-3.

31. Andrade SG, Campos RF, Steindel M, Guerreiro ML, Magalhaes JB, Almeida MC, et al. Biological, biochemical and molecular features of Trypanosoma cruzi strains isolated from patients infected through oral transmission during a 2005 outbreak in the state of Santa Catarina, Brazil: its correspondence with the new T. cruzi Taxonomy Consensus (2009). Mem Inst Oswaldo Cruz. 2011;106:948-56.

32. Monteiro WM, Magalhaes LK, de Sa AR, Gomes ML, Toledo MJ, Borges L, et al. Trypanosoma cruzi IV causing outbreaks of acute Chagas disease and infections by different haplotypes in the Western Brazilian Amazonia. PLoS One. 2012;7, e41284.

33. Ramirez JD, Montilla M, Cucunuba ZM, Florez AC, Zambrano P, Guhl F. Molecular epidemiology of human oral Chagas disease outbreaks in Colombia. PLoS Negl Trop Dis. 2013;7, e2041.

34. Muñoz-Calderon A, Diaz-Bello Z, Valladares B, Noya O, Lopez MC, Alarcón de Noya B, et al. Oral transmission of Chagas disease: typing of Trypanosoma cruzi from five outbreaks occurred in Venezuela shows multiclonal and common infections in patients, vectors and reservoirs. Infect Genet Evol. 2013;17:113-22.

35. Cáceres DNR, Corredor A, Gualdrón L, Slait E, Dib JC. Investigación de un brote de síndrome febril con miocarditis aguda en Guamal, Magdalena, 7 a 11 de junio de 1999. Colombia: Ministerio de Salud; 1999. p. 170-8.
36. Nicholls RS, Cucunubá ZM, Knudson A, Florez AC, Montilla M, Puerta CJ, et al. [Acute Chagas disease in Colombia: a rarely suspected disease. Report of 10 cases presented during the 2002-2005 period]. Biomedica. 2007;27 Suppl 1:8-17.

37. Nicholls RS, Cucunubá ZM, Flórez C, Montilla M. Enfermedad de Chagas agudo: Un incremento en el número de casos ocurridos en 2006 Colombia. Ministerio de Salud. 2007:367-78.

38. Zambrano PCZ, Montilla M, Flórez A, Edgar P, Ramirez AN, Echeverría L, et al. Brotes de Síndrome Febril Asociado a Miocarditis Aguda Chagásica de Posible Transmisión Oral en el Departamento de Santander, Colombia, diciembre de 2008 a mayo de 2009. Colombia: Ministerio de Salud; 2010. p. 17-26.

39. Moncayo A. () Chagas disease: current epidemiological trends after the interruption of vectorial and transfusional transmission in the Southern Cone countries. Mem Inst Oswaldo Cruz. 2003;98:577-91.

40. Guhl F, Restrepo M, Angulo VM, Antunes CM, Campbell-Lendrum D, Davies CR. Lessons from a national survey of Chagas disease transmission risk in Colombia. Trends Parasitol. 2005;21:259-62.

41. Miles MA, Toye PJ, Oswald SC, Godfrey DG. The identification by isoenzyme patterns of two distinct strain-groups of Trypanosoma cruzi, circulating independently in a rural area of Brazil. Trans R Soc Trop Med Hyg. 1977;71:217-25.

42. Goldberg SS, Chiari E. Growth and isolation of single colonies of Trypanosoma cruzi on solid medium. J Parasitol. 1980;66:677-9.

43. Souto RP, Fernandes O, Macedo AM, Campbell DA, Zingales B. DNA markers define two major phylogenetic lineages of Trypanosoma cruzi. Mol Biochem Parasitol. 1996;83:141-52

44. Brisse S, Verhoef J, Tibayrenc M. Characterisation of large and small subunit rRNA and mini-exon genes further supports the distinction of six Trypanosoma cruzi lineages. Int J Parasitol. 2001;31:1218-26.

45. de Freitas JM, Augusto-Pinto L, Pimenta JR, Bastos-Rodrigues L, Goncalves VF, Teixeira SM, et al. Ancestral genomes, sex, and the population structure of Trypanosoma cruzi. PLoS Pathog. 2006;2, e24.

46. Brisse S, Henriksson J, Barnabe C, Douzery EJ, Berkvens D, Serrano M, et al. Evidence for genetic exchange and hybridization in Trypanosoma cruzi based on nucleotide sequences and molecular karyotype. Infect Genet Evol. 2003;2:173-83.

47. Lewis MD, Ma J, Yeo M, Carrasco HJ, Llewellyn MS, Miles MA. Genotyping of Trypanosoma cruzi: systematic selection of assays allowing rapid and accurate discrimination of all known lineages. Am J Trop Med Hyg. 2009;81:1041-9.

48. TH. BioEdit: a user-friendly biological sequence alignment editor and analysis program for Windows 95/98/NT. Nucleic Acids Symp Ser. 1999;41:4.

49. Thompson JD, Gibson TJ, Plewniak F, Jeanmougin F, Higgins DG. The CLUSTAL_X windows interface: flexible strategies for multiple sequence alignment aided by quality analysis tools. Nucleic Acids Res. 1997;25:4876-82.

50. Molina-Berrios A, Campos-Estrada C, Lapier M, Duaso J, Kemmerling U, Galanti N, et al. Benznidazole prevents endothelial damage in an experimental model of Chagas disease. Acta Trop. 2013;127:6-13.

51. Spotorno OA, Cordova L, Solari A. Differentiation of Trypanosoma cruzi I subgroups through characterization of cytochrome b gene sequences. Infect Genet Evol. 2008;8:898-900.

52. Cura Cl, Mejia-Jaramillo AM, Duffy T, Burgos JM, Rodriguero M, Cardinal MV, et al. Trypanosoma cruzi I genotypes in different geographical regions and transmission cycles based on a microsatellite motif of the intergenic spacer of spliced-leader genes. Int J Parasitol. 2010;40:1599-607.

53. Campbell-Lendrum DH, Angulo VM, Esteban L, Tarazona Z, Parra GJ, Restrepo $\mathrm{M}$, et al. House-level risk factors for triatomine infestation in Colombia. Int J Epidemiol. 2007;36:866-72.

54. Angulo VM, Esteban L, Luna KP. Attalea butyracea palms adjacent to housing as a source of infestation by Rhodnius prolixus (Hemiptera: Reduviidae). Biomedica. 2012:32:277-85.

55. Pinto CM, Ocana-Mayorga S, Lascano MS, Grijalva MJ. Infection by trypanosomes in marsupials and rodents associated with human dwellings in Ecuador. J Parasitol. 2006;92:1251-5.

56. Bastos CJ, Aras R, Mota G, Reis F, Dias JP, de Jesus RS, et al. Clinical outcomes of thirteen patients with acute chagas disease acquired through oral transmission from two urban outbreaks in northeastern Brazil. PLoS Negl Trop Dis. 2010;4, e711.

57. Rios JF, Arboleda M, Montoya AN, Alarcon EP. Probable outbreak of oral transmission of Chagas disease in Turbo, Antioquia. Biomedica. 2011;31:185-95.

58. Muñoz C, Zulantay I, Apt W, Ortiz S, Schijman AG, Bisio M, et al. Evaluation of nifurtimox treatment of chronic Chagas disease by means of several parasitological methods. Antimicrob Agents Chemother. 2013;57:4518-23.

59. Muñoz-Calderón A, Santaniello A, Pereira A, Jannuzzi J, Díaz-Bello Z, Alarcón de Noya B. Susceptibilidad in vitro a Nifurtimox y Benznidazole de aislados 
de Trypanosoma cruzi obtenidos de pacientes venezolanos con enfermedad de Chagas infectados por mecanismos de transmisión oral y vectorial. Rev Ibero-Latinoam Parasitol. 2012;71(1):14-22.

60. Pinto AY, Valente Vda C, Coura JR, Valente SA, Junqueira AC, Santos LC, et al. Clinical follow-up of responses to treatment with benznidazol in Amazon: a cohort study of acute Chagas disease. PLoS One. 2013;8, e64450.

61. Toledo MJ, Bahia MT, Carneiro CM, Martins-Filho OA, Tibayrenc M, Barnabé C, et al. Chemotherapy with benznidazole and itraconazole for mice infected with different Trypanosoma cruzi clonal genotypes. Antimicrob Agents Chemother. 2003;47:223-30.

62. Teston AP, Monteiro WM, Reis D, Bossolani GD, Gomes ML, de Araújo SM, et al. In vivo susceptibility to benznidazole of Trypanosoma cruzi strains from the western Brazilian Amazon. Trop Med Int Health. 2013:18:85-95.

63. Martinez I, Nogueda B, Martinez-Hernandez F, Espinoza B. Microsatellite and mini-exon analysis of Mexican human DTU I Trypanosoma cruzi strains and their susceptibility to nifurtimox and benznidazole. Vector Borne Zoonotic Dis. 2013;13:181-7.

\section{Submit your next manuscript to BioMed Central} and we will help you at every step:

- We accept pre-submission inquiries

- Our selector tool helps you to find the most relevant journal

- We provide round the clock customer support

- Convenient online submission

- Thorough peer review

- Inclusion in PubMed and all major indexing services

- Maximum visibility for your research 